\title{
Predictors of methotrexate response in Turkish children with oligoarticular and polyarticular juvenile idiopathic arthritis
}

\author{
Ezgi Deniz Batu¹, Hafize Emine Sönmez¹, Bora Gülhan², Zehra Serap Arıc1 ${ }^{1}$, Rezan \\ Topaloğlu ${ }^{2}$, Yelda Bilginer ${ }^{1}$ \\ ${ }^{1}$ Division of Rheumatology, ${ }^{2}$ Division of Nephrology, Department of Pediatrics, Hacettepe University Faculty of Medicine, \\ Ankara, Turkey. \\ E-mail: yeldabilginer@yahoo.com \\ Received: 10th August 2016, Revised: 24th January 2017, Accepted: 10th May 2017
}

SUMMARY: Batu ED, Sönmez HE, Gülhan B, Arıcı ZS, Topaloğlu R, Bilginer Y. Predictors of methotrexate response in Turkish children with oligoarticular and polyarticular juvenile idiopathic arthritis. Turk J Pediatr 2017; 59: 6-12.

Methotrexate (MTX) is the most commonly used disease modifying antirheumatic drug in juvenile idiopathic arthritis (JIA). We aimed to define predictor factors for response to MTX in Turkish children with oligo- and polyarticular JIA. We reviewed the medical files of 59 oligo- and 57 polyarticular JIA patients seen in the clinic between May 2008 and May 2013 and who received MTX for $\geq 6$ months. MTX responders were defined as having no/ low disease activity according to juvenile arthritis disease activity score 71 (JADAS71) at 6 months after MTX initiation. Median age at JIA diagnosis/ MTX initiation was 70/78 months. Involvement of the small or upper extremity joints at disease diagnosis and MTX initiation was more frequent; antinuclear antibody (ANA) positivity was less frequent; acute phase reactants, JADAS71 at MTX initiation, and the frequency of polyarticular subtype were higher in MTX non-responders. In multiple logistic regression, oligoarticular JIA subtype and ANA positivity were independent predictors of MTX response.

Key words: juvenile idiopathic arthritis, methotrexate, oligoarticular, polyarticular, treatment.

Juvenile idiopathic arthritis (JIA) is the most common chronic rheumatologic disease of childhood with an incidence of 19.8 per 100,000 Caucasian children under the age of $16^{1}$. In Turkey, the prevalence of JIA is reported to be $64 / 100,000$ children $^{2}$. JIA represents a group of heterogeneous diseases that are classified as arthritis of unknown origin and have onset before the age of 16 years ${ }^{3}$.

JIA is divided into six distinct categories according to the International League of Associations for Rheumatology (ILAR) classification: oligoarticular, polyarticular, systemic, psoriatic, enthesitis related and unclassified arthritis, ${ }^{4}$.

The principle aim of JIA treatment is to achieve clinically inactive disease while preventing long-term morbidities. A variety of therapies are currently used in the management of JIA, including both biologic and non-biologic diseasemodifying anti-rheumatic drugs (DMARDs). In
2011, the American College of Rheumatology (ACR) published recommendations for the safest and most effective treatment of JIA ${ }^{6}$. Afterwards in 2014, the Childhood Arthritis and Rheumatology Research Alliance (CARRA) developed three consensus treatment plans (CTPs) for new-onset polyarticular $\mathrm{JIA}^{7}$.

Methotrexate (MTX) has been used for more than 25 years and is the most commonly used first-line DMARD in $\mathrm{JIA}^{8}$. It is a safe and inexpensive drug. However, MTX is ineffective in approximately $30 \%$ of JIA patients ${ }^{8}$. With the increasing availability of biologic therapies, it is important to predict and identify patients who will not benefit from MTX in order to allow these patients to start using biologic drugs in the early phases of the disease before morbidities develop. Previous studies have reported various factors that are predictive for MTX efficacy ${ }^{8-10}$. However, these factors may differ between ethnic groups. In this study, our aim was to define predictor factors for 
the response to MTX in Turkish children with oligo- and polyarticular JIA.

\section{Material and Methods}

We retrospectively reviewed the medical files of children (aged 0-18 years) seen at our hospital between May 2008 and May 2013 who were diagnosed with oligo- or polyarticular JIA and who received MTX treatment $\left(12.5 \mathrm{mg} / \mathrm{m}^{2} /\right.$ week) for at least six months. These patients were classified as having JIA according to the ILAR criteria ${ }^{4}$. Demographic data, clinical manifestations, laboratory data (white blood cell [WBC] count, erythrocyte sedimentation rate [ESR], C-reactive protein [CRP], anti-nuclear antibody [ANA] positivity, rheumatoid factor [RF] positivity), patient/parent visual analogue scale (VAS), physician VAS, and the use of concomitant treatment (such as nonsteroidal anti-inflammatory drugs [NSAIDs] and intraarticular steroid injection) were documented. $M E F V$ gene variant analysis was performed in some patients (patients with typical periodic fever phenotype or patients who had high CRP for long term despite treatment) by Sanger sequencing and 12 mutations (E148Q, P369S, F479I, M680I (G-C), M680I (G-A), I692del, M694V, M694I, K695R, V726A, A744S, R761H) were tested in the $M E F V$ gene. Juvenile arthritis disease activity score 71 (JADAS71) was used to evaluate disease activity. The JADAS 71 is a measure of disease activity in JIA patients and is based on four factors: (1) physician's global assessment of disease activity on a $0-10$ visual analog scale (VAS); (2) parent/patient global assessment of well-being on a $0-10$ VAS; (3) count of joints with active arthritis, and (4) erythrocyte sedimentation rate (ESR). It is calculated using the formula: physician's VAS + patient's VAS + count of joints with active arthritis + (ESR-20)/10. 11-13. MTX responders were defined as patients whose disease was inactive or who had low disease activity according to JADAS71 at 6 months after MTX initiation. Patients with oligoarticular JIA were classified as having inactive disease if JADAS71 was $<1$ and having low disease activity if JADAS71 was 1-2. In addition, patients with polyarticular JIA were classified as having inactive disease if JADAS71 was < 1 , and having low disease activity if JADAS71 was between 1.1-3.814.

The study was reviewed and approved by the ethical review committee of our hospital.

\section{Statistical Analysis}

Statistical analyses were performed using the SPSS software version 15. Descriptive analyses are presented using proportions, medians, range values as appropriate. The $\chi^{2} /$ Fischer and Mann Whitney U tests were used to compare non-normally distributed variables between independent two groups. The Wilcoxon test was used to compare the non-normally distributed variables between dependent groups. The effects of different parameters (age at diagnosis, subtype of JIA [polyarticular or oligoarticular], ANA positivity, RF positivity age, active joint number, WBC count, ESR, CRP, patient/parent VAS, physician VAS, and JADAS71 at MTX initiation) on MTX response were calculated using simple logistic regression analysis. The variables for which the unadjusted $\mathrm{P}$ value was $<0.20$ in simple logistic regression analysis were included in the full model. We reduced the model by using backward elimination of multiple logistic regression analyses and we eliminated potential risk markers using likelihood ratio tests. A P-value $<0.05$ was considered a statistically significant result.

\section{Results}

A total of 116 patients were included in this study. Females ( $\mathrm{n}=76 ; 65.5 \%$ ) outnumbered males. The median age at JIA diagnosis was 70 months (range: 7-180) while age at MTX initiation was 78 months (range: 12-183). The median duration between diagnosis and initiation of MTX treatment was 0 months (range: 0-156). The median duration of MTX treatment was 12 months (range: 6-78) months. The median follow-up after MTX initiation was 36 months (range: 12-148). Of 116 patients, $51(43.9 \%)$ had persistent oligoarticular JIA, eight had extended oligoarticular JIA, and 57 $(49.1 \%)$ had polyarticular JIA. In oligoarticular JIA patients, both disease diagnosis and MTX initiation occurred at a younger median age when compared to the polyarticular JIA patients (54 vs. $86, \mathrm{P}=0.007$ and 66 vs. $102, \mathrm{P}=$ 0.032 , respectively). The median number of active joints was 4 (range: 1-36) at diagnosis and 5 (range: 1-22) at MTX initiation. There was a decrease in the range of motion in 3 (range: 0-24) and 3 (range: 0-20) joints at diagnosis and MTX initiation, respectively. At diagnosis, 58 (50\%) had arthritis in the 
Table I. The Characteristics of Methotrexate Responder and Non-Responder Juvenile Idiopathic Arthritis Patients

\begin{tabular}{|c|c|c|c|}
\hline & $\begin{array}{l}\text { Responders } \\
(\mathrm{n}=72)^{\mathrm{a}}\end{array}$ & $\begin{array}{l}\text { Non-responders } \\
(\mathrm{n}=44)^{\mathrm{a}}\end{array}$ & $P$ value \\
\hline \multicolumn{4}{|l|}{ Patient characteristics } \\
\hline Gender, female & $49 / 72(68 \%)$ & $27 / 44(61.3 \%)$ & 0.46 \\
\hline Age at diagnosis (months) & $66(7-180)$ & $78(14-180)$ & 0.47 \\
\hline Age at MTX initiation (months) & $74(12-181)$ & $84(14-183)$ & 0.99 \\
\hline \multicolumn{4}{|l|}{ Joint involvement } \\
\hline Polyarticular JIA & $23 / 72(31.9 \%)$ & $34 / 44(77.2 \%)$ & $<0.001$ \\
\hline Involvement of small joints at diagnosis & $27 / 72(37.5 \%)$ & $30 / 44(68.1 \%)$ & 0.001 \\
\hline Involvement of small joints at MTX initiation & $29 / 72(40.2 \%)$ & $30 / 44(68.1 \%)$ & 0.003 \\
\hline Involvement of upper extremity joints at diagnosis & $29 / 72(40 \%)$ & $29 / 44(65.9 \%)$ & 0.007 \\
\hline $\begin{array}{l}\text { Involvement of upper extremity joints at MTX } \\
\text { initiation }\end{array}$ & $34 / 72(47.2 \%)$ & $29 / 44(65.9 \%)$ & 0.049 \\
\hline No of active joints at MTX initiation & $3(1-22)$ & $7(1-22)$ & $<0.001$ \\
\hline \multicolumn{4}{|l|}{ Laboratory findings } \\
\hline WBC count at MTX initiation & $9.5(4-19.1)$ & $10.3(6.6-33)$ & 0.23 \\
\hline ESR at MTX initiation & $42(13-100)$ & $57.5(12-145)$ & 0.036 \\
\hline CRP at MTX initiation & $2(0.12-12.8)$ & $4.2(0.1-14.2)$ & 0.026 \\
\hline RF positivity & $2 / 66(3 \%)$ & $4 / 38(10.5 \%)$ & 0.18 \\
\hline ANA positivity & $25 / 59(42 \%)$ & $6 / 34(17.6 \%)$ & 0.015 \\
\hline \multicolumn{4}{|l|}{ Treatment } \\
\hline NSAID use & $40 / 72(55.5 \%)$ & $31 / 44(70.4 \%)$ & 0.11 \\
\hline Systemic steroid use & $18 / 72(25 \%)$ & $15 / 44(34 \%)$ & 0.29 \\
\hline Intraarticular steroid injection & $29 / 54(53.7 \%)$ & $13 / 29(44.8 \%)$ & 0.44 \\
\hline \multicolumn{4}{|l|}{ Disease activity } \\
\hline Physician VAS at MTX initiation & $3(1-5)$ & $3(1-6)$ & 0.041 \\
\hline JADAS71 at MTX initiation & $11.4(0.5-40)$ & $18(5.9-41)$ & $<0.001$ \\
\hline
\end{tabular}

aData expressed as numbers (\%) or median (range) value

JIA, juvenile idiopathic arthritis; MTX, methotrexate; WBC, white blood cell $\left(\mathrm{x}^{1} \mathrm{O}^{3} / \mathrm{mm}^{3}\right)$; ESR, erythrocyte sedimentation rate $(\mathrm{mm} / \mathrm{h}$; normal range $0-20)$; CRP, C-reactive protein $(\mathrm{mg} / \mathrm{dl}$, normal range 0-0.8); VAS, visual analogue scale (0-10 cm, 10 worst); JADAS71, juvenile arthritis disease activity score 71; RF, rheumatoid factor; ANA, antinuclear antibody; NSAID, nonsteroidal anti-inflammatory drug

joints of the upper extremities and 57 (49.1\%) had small joint arthritis. At MTX initiation, $63(54.3 \%)$ had arthritis in the joints of the upper extremities and 59 (50.8\%) had small joint arthritis. The median WBC count was 9.8 (range: $4-33.6$ ) $\times 10^{3} / \mathrm{mm}^{3}$, ESR was 49.5 (range: $12-145$ ) $\mathrm{mm} / \mathrm{h}$, CRP was 2.86 (range: 0-14.3), patient/parent VAS was 3 (range: 2-7), physician VAS was 3 (range: 1-6), and JADAS71 was 13.15 (range: 0.5-41) at the time of MTX initiation. ANA positivity was present in $31(26.7 \%)$ patients. Seventy-one $(61.2 \%)$ patients received NSAIDs and 33 (28.4\%) received systemic steroid treatment. Intra-articular steroid injection was performed in $33(28.4 \%)$ patients.

The characteristics of MTX responders and non- responders in the whole group and oligo- and polyarticular JIA subgroups are summarized in Table I and Table II. No significant difference was present between the MTX responders and non-responders or oligo- and polyarticular JIA subgroups in terms of age, gender, or age at MTX initiation. In the study cohort, the involvement of the small joints or upper extremity joints at disease diagnosis and MTX initiation was more frequent, ANA positivity was less frequent in MTX non-responders in comparison with MTX responders. The frequency of the polyarticular subtype, acute phase reactants (ESR, CRP) and JADAS71 at MTX initiation was higher in the MTX nonresponder group as well. The median (range) values for active joint number, WBC count, ESR, CRP, patient/parent VAS, physician VAS, 
JADAS71 at MTX initiation were significantly decreased after 6 months of treatment in comparison to MTX initiation (Table III). There was no statistically significant difference between the characteristics of MTX responders and non-responders in the subgroup (oligo- and polyarticular JIA) analysis. In addition, there was no significant difference between persistent and extended oligoarticular JIA patients with regard to MTX response. At multiple logistic regression, JIA subtype and ANA positivity were independent predictors of MTX response. Oligoarticular JIA subtype was associated with a 7 -fold increase $(\mathrm{P}<0.001)$ and ANA positivity

Table II. Characteristics of Methotrexate Responders and Non-Responders in Oligo-, and Polyarticular JIA Subgroups

\begin{tabular}{|c|c|c|c|c|c|c|}
\hline \multirow[t]{2}{*}{ Characteristics } & \multicolumn{2}{|c|}{ Oligoarticular JIA $(n=59)$} & \multirow[b]{2}{*}{$\begin{array}{l}\mathrm{P} \\
\text { value }\end{array}$} & \multicolumn{3}{|c|}{ Polyarticular JIA $(\mathrm{n}=57)$} \\
\hline & $\begin{array}{l}\text { Responders } \\
(\mathrm{n}=49)^{\mathrm{a}}\end{array}$ & $\begin{array}{l}\text { Non- } \\
\text { responders } \\
(\mathrm{n}=10)^{\mathrm{a}}\end{array}$ & & $\begin{array}{l}\text { Responders } \\
(\mathrm{n}=23)^{\mathrm{a}}\end{array}$ & $\begin{array}{l}\text { Non- } \\
\text { responders } \\
(\mathrm{n}=34)^{\mathrm{a}}\end{array}$ & $\begin{array}{l}\mathrm{P} \\
\text { value }\end{array}$ \\
\hline \multicolumn{7}{|l|}{ Patient characteristics } \\
\hline Gender, female & $36 / 49$ & $6 / 10$ & 0.45 & $13 / 23$ & $21 / 34$ & 0.69 \\
\hline $\begin{array}{l}\text { Age at diagnosis } \\
\text { (months) }\end{array}$ & $54(7-180)$ & $70(14-162)$ & 0.41 & $113(12-174)$ & $81(14-180)$ & 0.32 \\
\hline $\begin{array}{l}\text { Age at MTX initiation } \\
\text { (months) }\end{array}$ & $60(12-181)$ & $90(15-162)$ & 0.63 & $114(36-174)$ & $84(14-183)$ & 0.13 \\
\hline \multicolumn{7}{|l|}{ Joint involvement } \\
\hline $\begin{array}{l}\text { Involvement of small } \\
\text { joints at diagnosis }\end{array}$ & $11 / 49$ & $2 / 10$ & 1 & $16 / 23$ & $28 / 34$ & 0.25 \\
\hline $\begin{array}{l}\text { Involvement of upper } \\
\text { extremity joints at } \\
\text { diagnosis }\end{array}$ & $9 / 49$ & $2 / 10$ & 1 & $20 / 23$ & $27 / 34$ & 0.72 \\
\hline $\begin{array}{l}\text { No of active joints at } \\
\text { MTX initiation } \\
\text { Laboratory features }\end{array}$ & $2(1-12)$ & $2(1-7)$ & 0.97 & $6(5-22)$ & $8.5(5-22)$ & 0.22 \\
\hline $\begin{array}{l}\text { WBC count at MTX } \\
\text { initiation }\end{array}$ & $9.7(4-19.1)$ & $11.3(8.3-21)$ & 0.14 & $9.1(5.5-18.3)$ & $\begin{array}{l}10.1(6.6- \\
33.6)\end{array}$ & 0.38 \\
\hline ESR at MTX initiation & $40(19-92)$ & $48.5(33-76)$ & 0.23 & $50(13-100)$ & $60(12-145)$ & 0.63 \\
\hline CRP at MTX initiation & $2(0.5-23)$ & $6.8(1-10.6)$ & 0.12 & $2.2(0.1-12.8)$ & $3.6(0-14.2)$ & 0.14 \\
\hline \multicolumn{7}{|l|}{ Treatment } \\
\hline NSAID use & $27 / 49$ & $5 / 10$ & 1 & $13 / 23$ & $26 / 34$ & 0.11 \\
\hline Systemic steroid use & $11 / 49$ & $4 / 10$ & 0.25 & $7 / 23$ & $11 / 34$ & 0.87 \\
\hline $\begin{array}{l}\text { Intraarticular steroid } \\
\text { injection }\end{array}$ & $27 / 35$ & $4 / 6$ & 0.62 & $2 / 19$ & $9 / 23$ & 0.07 \\
\hline \multicolumn{7}{|l|}{ Disease activity } \\
\hline $\begin{array}{l}\text { Patient/parent VAS at } \\
\text { MTX initiation }\end{array}$ & $3(2-5)$ & $3(2-4)$ & 0.66 & $4(3-6)$ & $4(3-7)$ & 0.50 \\
\hline $\begin{array}{l}\text { Physician VAS at MTX } \\
\text { initiation }\end{array}$ & $2(1-4)$ & $2.5(1-4)$ & 0.82 & $3(2-5)$ & $3(2-6)$ & 0.84 \\
\hline $\begin{array}{l}\text { JADAS71 at MTX } \\
\text { initiation }\end{array}$ & $9.1(0.5-23.8)$ & $12(5.9-19.7)$ & 0.47 & $20(11-40)$ & $19.2(10.3-41)$ & 0.77 \\
\hline
\end{tabular}

aData expressed as numbers (\%) or median (range) values

JIA, juvenile idiopathic arthritis; MTX, methotrexate; WBC, white blood cell $\left(\mathrm{x}_{10} \mathrm{3} / \mathrm{mm}^{3}\right)$; ESR, erythrocyte sedimentation rate $(\mathrm{mm} / \mathrm{h}$; normal range $0-20)$; CRP, C-reactive protein $(\mathrm{mg} / \mathrm{dl}$, normal range $0-0.8)$; VAS, visual analogue scale (0-10 $\mathrm{cm}, 10$ worst); JADAS71, juvenile arthritis disease activity score 71; RF, rheumatoid factor; ANA, antinuclear antibody; NSAID, nonsteroidal anti-inflammatory drug 
Table III. Disease Related Parameters at Initiation and $6^{\text {th }}$ Month of Methotrexate (MTX) Treatment

\begin{tabular}{llll}
\hline Parameters & At initiation of MTX treatment & $6^{\text {th }}$ month $^{\mathrm{a}}$ & P value \\
\hline Active joint count & $5(1-22)$ & $0.5(0-18)$ & $<0.001$ \\
WBC & $9.8(4-33.6)$ & $8.8(3.8-28.5)$ & 0.007 \\
ESR & $49.5(12-145)$ & $20(0-120)$ & $<0.001$ \\
CRP & $2.8(0.1-12.8)$ & $0.6(0-26)$ & $<0.001$ \\
Patient/parent VAS & $3(2-7)$ & $2(0-7)$ & $<0.001$ \\
Physician VAS & $3(1-6)$ & $1(0-6)$ & $<0.001$ \\
JADAS71 & $13.1(0.5-41)$ & $4.9(0-41)$ & $<0.001$ \\
\hline
\end{tabular}

${ }^{a}$ Data expressed as median (range) values.

MTX, methotrexate; WBC, white blood cell $\left(\mathrm{x} 10^{3} / \mathrm{mm}^{3}\right)$; ESR, erythrocyte sedimentation rate $(\mathrm{mm} / \mathrm{h}$; normal range $0-20)$; CRP, C-reactive protein $(\mathrm{mg} / \mathrm{dl}$, normal range $0-0.8)$;

VAS, visual analogue scale $(0-10 \mathrm{~cm}, 10$ worst); JADAS71, juvenile arthritis disease activity score 71

was associated with a 2.5 -fold increase $(\mathrm{P}=$ 0.049) in the likelihood of MTX response

Thirty-six patients had been tested for MEFV variants. Nine patients had accompanying familial Mediterranean fever (FMF) with typical fever attacks and were using colchicine (6 M694V/M694V, 1 V726A/V726A, 1 M680I/ V726A, and 1 with V726A/P369S). Fourteen were negative for the $M E F V$ variants evaluated and 13 were heterozygous for different variants (4 for E148Q, 4 for M694V, 2 for M680I, and 1 each for A744S, V726A, and K695R). There were no fever attacks in these 27 patients. There were no differences with regard to the $M E F V$ variants between MTX responders and non-responders. There were 22 patients positive for $M E F V$ variants. Fourteen $(63.6 \%)$ of them had oligoarticular JIA and 8 $(36.4 \%)$ had polyarticular JIA. There were no significant differences with regard to JIA disease characteristics and response between patients positive for $M E F V$ variants $(\mathrm{n}=22)$ and patients negative for $M E F V$ variants $(n=14)$. Seven out of 9 FMF patients had oligoarticular JIA and two had polyarticular JIA. Four FMF+JIA patients were MTX non-responders. When we compared FMF+JIA patients $(n=9)$ with other JIA patients $(n=107)$, we saw that the active joint number at MTX initiation was lower in the FMF group than in the other groups (median values 2 vs 5 , respectively; $\mathrm{P}=0.031$ ). The ratio of polyarticular JIA patients was higher in the non-FMF group than in the FMF patients ( $51.4 \%$ vs $22.2 \%$, respectively); however, this difference was not statistically significant. In addition, there was no significant difference with regard to the MTX response between the two groups (non-responders $44.4 \%$ in FMF and $37.4 \%$ in non-FMF group). Of note, all FMF patients were receiving colchicine therapy at the time of JIA diagnosis.

\section{Discussion}

Among our study population primary factors associated with MTX response were involvement of small joints or upper extremity joints, polyarticular or oligoarticular subtype, acute phase reactant levels, JADAS71 values, and ANA positivity. In multiple logistic regression analysis, only the JIA subtype (oligo or polyarticular) and ANA positivity were found to be independent predictors of MTX response. Patients with oligoarticular JIA or positive ANA test have a greater probability of response to MTX treatment.

Juvenile idiopathic arthritis (JIA) is the most common cause of chronic arthritis in childhood. The principle aim of treatment for JIA is rapid disease control and the prevention of irreversible joint damage. Despite considerable variation in response to MTX among patients, MTX is still a strong, cost-effective, and safe drug in JIA. However, identifying the risk factors for poor MTX response is important for providing effective therapies for high risk patients and the prevention of disease complications. Previous studies have reported conflicting results regarding factors predicting MTX response in JIA patients. At first, several researchers evaluated the effect of MTX according to the type of JIA. Halle and Prieur ${ }^{15}$ demonstrated that the systemic form of JIA was less responsive to MTX treatment 
than polyarticular-onset JIA ${ }^{15}$. Another study by Ravelli et al. ${ }^{16}$ extended the oligoarticular category of JIA which was found to be the best predictor of MTX efficacy. On the other hand, Woo et al. ${ }^{1}$ demonstrated that MTX is an effective treatment for both extended oligoarticular and systemic JIA. In our study, we found that oligoarticular JIA resulted in a better MTX response than polyarticular JIA.

The Pediatric Rheumatology International Trials Organization (PRINTO) designed an MTX trial to determine the factors associated with response to MTX. According to this study, patients with longer disease duration, ANA negativity, higher disability, and presence of wrist activity were more likely to have a poor response to a 6-month MTX course ${ }^{10}$. In our study, ANA negativity and involvement of the upper extremities were more common the non-responders, consistent with the results of PRINTO study. In another study, Albarouni et al. ${ }^{9}$ that a longer disease duration, lower number of active joints, higher number of tender joints, lower score of parents' evaluation of child's pain at baseline were risk factors associated with absence of PedACR 70 response, while the presence of morning stiffness was a positive predictor for PedACR 70. Our results demonstrated that the disease was more active (higher number of active joints, higher acute phase reactant levels and JADAS71 values) in the MTX non-responders. In a recent systematic review, van Dijkhuizen et al. ${ }^{8}$ demonstrated that different parameters such as the childhood health assessment questionnaire (CHAQ) score, physician's global assessment, bilateral wrist involvement, ANA positivity, S100A8/A9 levels, osteopontin levels, and single nucleotide polymorphisms (SNPs) in several gene regions were candidate predictors.

According to the ACR recommendations, the physician should consider MTX for patients with oligo- and polyarticular JIA if the disease is not under control with intra-articular injections and/or 1-2 months treatment with NSAIDs ${ }^{6}$. If disease activity is moderate-high after three months of MTX treatment, biologic treatment should be initiated. If disease activity is high after 6 months of treatment in persistent oligoarticular JIA and low in extended oligoarticular and polyarticular JIA, biologic treatment should be started irrespective of the prognostic factors. The prognostic factors for oligoarticular and polyarticular JIA were arthritis of the hip, cervical spine, ankle, or wrist, prolonged inflammatory marker elevation, positive rheumatoid factor, and radiographic damage ${ }^{6}$. We have included the involvement of small joints and upper extremity joints in our database and found that the patients in the MTX non-responder group tended to have more small joint/upper extremity joint involvement at disease diagnosis and at MTX initiation.

CARRA CTPs for new-onset polyarticular JIA were as follows: step-up CTP, early combination (biologic + nonbiologic DMARD) $\mathrm{CTP}$, and biologic only $\mathrm{CTP}^{7}$. According to CARRA step-up CTP, treatment starts with a non-biologic DMARD ( \pm prednisolone, intraarticular steroid injections), and the physician should consider increasing/changing DMARD or beginning biologic treatment if the patient does not improve substantially (physician global assessment $>2$ and/or still on prednisolone) at $3^{\text {rd }}$ month visit. We may bypass the stepup CTP in patients with predictors for poor response to MTX.

An increased incidence of $M E F V$ mutations has been shown among patients with vasculitis, chronic arthritis, and inflammatory bowel disease ${ }^{17}$. Ozen et al. ${ }^{18}$ found that 6 out of 59 JIA patients, were homozygous or compound heterozygous for MEFV mutations. Özçakar et al. ${ }^{17}$ showed that there was FMF in $3.5 \%$ of JIA patients. In our study $7.75 \%$ of patients had FMF and were treated with colchicine. Colchicine is the standard treatment of choice in FMF, but it is also used in other rheumatic disease such as vasculitis, autoinflammatory disease, and gout. Our FMF+JIA patients had a lower number of active joints at MTX initiation and all of them were receiving colchicine therapy. Colchicine may have a positive effect for arthritis control.

The limitations of our study are the retrospective design and the small number of patients.

In conclusion, we have demonstrated that oligoarticular subtype of JIA and ANA positivity are strong candidate predictors for MTX efficacy. Future prospective studies with more patients will be crucial for defining the exact factors identifying patients who are at risk of not responding to MTX treatment. These factors will help us improve our selection of the most 


\section{appropriate treatment in JIA.}

\section{REFERENCES}

1. Woo P, Southwood TR, Prieur AM, et al. Randomized, placebo-controlled, crossover trial of low-dose oral methotrexate in children with extended oligoarticular or systemic arthritis. Arthritis Rheum 2000; 43: 18491857.

2. Ozen S, Karaaslan Y, Ozdemir O, et al. Prevalence of juvenile chronic arthritis and familial Mediterranean fever in Turkey: a field study. J Rheumatol 1998; 25 : 2445-2449.

3. Prakken B, Albani S, Martini A. Juvenile idiopathic arthritis. Lancet 2011; 377: 2138-2149.

4. Petty RE, Southwood TR, Baum J, et al. Revision of the proposed classification criteria for juvenile idiopathic arthritis: Durban, 1997. J Rheumatol 1998; 25: 19911994.

5. Petty RE, Southwood TR, Manners P, et al. International League of Associations for Rheumatology classification of juvenile idiopathic arthritis: second revision, Edmonton, 2001. J Rheumatol 2004; 31: 390-392.

6. Beukelman T, Patkar NM, Saag KG, et al. 2011 American College of Rheumatology recommendations for the treatment of juvenile idiopathic arthritis: initiation and safety monitoring of therapeutic agents for the treatment of arthritis and systemic features. Arthritis Care Res (Hoboken) 2011; 63: 465-482.

7. Ringold S, Weiss PF, Colbert RA, et al. Childhood Arthritis and Rheumatology Research Alliance consensus treatment plans for new-onset polyarticular juvenile idiopathic arthritis. Arthritis Care Res (Hoboken) 2014; 66: 1063-1072.

8. van Dijkhuizen EH, Wulffraat NM. Prediction of methotrexate efficacy and adverse events in patients with juvenile idiopathic arthritis: a systematic literature review. Pediatr Rheumatol Online J 2014; 12: 51.

9. Albarouni M, Becker I, Horneff G. Predictors of response to methotrexate in juvenile idiopathic arthritis. Pediatr Rheumatol Online J 2014; 12: 35.

10. Vilca I, Munitis PG, Pistorio A, et al. Predictors of poor response to methotrexate in polyarticular-course juvenile idiopathic arthritis: analysis of the PRINTO methotrexate trial. Ann Rheum Dis 2010; 69: 14791483.

11. Consolaro A, Ruperto N, Bazso A, et al. Development and validation of a composite disease activity score for juvenile idiopathic arthritis. Arthritis Rheum 2009; 61: 658-666.

12. McErlane F, Beresford MW, Baildam EM, et al. Validity of a three-variable Juvenile Arthritis Disease Activity Score in children with new-onset juvenile idiopathic arthritis. Ann Rheum Dis 2013; 72: 1983-1988.

13. Consolaro A, Ravelli A. Defining criteria for disease activity states in juvenile idiopathic arthritis. Rheumatology (Oxford) 2016, 55: 595-596

14. Demirkaya E, Consolaro A, Sonmez HE, Giancane G, Simsek D, Ravelli A. Curren Research in Outcome Measures for Pediatric Rheumatic and Autoinflammatory Diseases. Curr Rheumatol Rep 2016; 18: 8.

15. Halle F, Prieur AM. Evaluation of methotrexate in the treatment of juvenile chronic arthritis according to the subtype. Clin Exp Rheumatol 1991; 9: 297-302.

16. Ravelli A, Viola S, Migliavacca D, Ruperto N, Pistorio A, Martini A. The extended oligoarticular subtype is the best predictor of methotrexate efficacy in juvenile idiopathic arthritis. J Pediatr 1999; 135: 316-320.

17. Ozcakar ZB, Cakar N, Uncu N, Celikel BA, Yalcinkaya F. Familial Mediterranean fever-associated diseases in children. QJM 2016.

18. Ozen S, Bakkaloglu A, Yilmaz E, et al. Mutations in the gene for familial Mediterranean fever: do they predispose to inflammation? J Rheumatol 2003; 30: 2014-2018. 